\title{
Pequenas grandes violências: uma análise do preconceito relacionado a gênero
}

\author{
Mariana Cristina Marino1, Rita C. G. Berardi², Silvia Amelia Bim² \\ ${ }^{1}$ Departamento Acadêmico de Linguagem e Comunicação \\ Universidade Tecnológica Federal do Paraná (UTFPR) - Curitiba - Brasil \\ ${ }^{2}$ Departamento Acadêmico de Informática (DAINF) \\ Universidade Tecnológica Federal do Paraná (UTFPR) - Curitiba - Brasil \\ mariana.cmarinodgmail.com, \{ritaberardi,sabim\}@utfpr.edu.br
}

\begin{abstract}
The objective of the present work is to analyze the results of the public reaction to situations of gender-related prejudice and exemplified in small dramatizations developed by the Revanche Drama Company in the event of International Women's Day organized by the Emili@s extension project. The results reveal that the male's and female's perception is strongly divergent.
\end{abstract}

Resumo. O objetivo do presente trabalho é analisar os resultados da reação do público frente a situações de preconceito relacionado a gênero e exemplificadas em pequenas dramatizações desenvolvidas pelo grupo de Teatro Revanche em evento do Dia Internacional da Mulher, organizado pelo projeto de extensão Emíli@s. Os resultados revelam que as percepções de pessoas dos gêneros masculinos e femininos são bastante divergentes.

\section{Introdução}

Nos últimos anos, no contexto da Computação, diversas ações são realizadas mundialmente para aumentar a participação das mulheres nesta área [Nunes et al. 2016a, 2016b]. No Brasil novas iniciativas, tanto no cenário educacional quanto empresarial, são criadas a cada ano.

O projeto Emíli@s - Armação em Bits é um exemplo destas iniciativas, desenvolvido como extensão na Universidade Tecnológica Federal do Paraná (UTFPR), campus Curitiba. O principal objetivo do projeto é apresentar a Computação para meninas, estudantes do ensino médio, de modo que elas possam considerar a área como uma possibilidade de atuação profissional. Busca-se alcançar este objetivo através de mesas redondas, palestras sobre temas diversos da Computação e áreas afins, relatos de vida e motivacionais, encontros e oficinas.

O grupo de teatro Revanche existe na UTFPR-Curitiba como um projeto de extensão desde 2011. Sempre com a proposta de desenvolver textos sociais e políticos, o Revanche já produziu, em seu repertório, 5 peças. O projeto é fruto de uma disciplina optativa do curso de Licenciatura em Letras e atualmente o grupo conta com a participação de estudantes egressos(as) e licenciandos(as) da área e estudantes de Design, Comunicação Institucional e Arquitetura.

Neste artigo relata-se a primeira atividade em parceria entre estes dois projetos de extensão. 


\section{Metodologia}

A partir de nove cenas curtas ${ }^{1}$, o grupo de teatro Revanche teve o intuito de denunciar casos baseados em relatos reais de violência, muitas vezes silenciosa, enfrentados cotidianamente pelas mulheres. As cenas foram apresentadas como parte da programação em alusão ao Dia Internacional da Mulher em 2017. No momento da apresentação, executada por 7 dos 13 atores do grupo de teatro, estavam presentes aproximadamente 40 espectadores(as), convidados(as) de todos os cursos e departamentos da UTFPR-Curitiba.

Para cada pessoa do público presente foi entregue um formulário para avaliarem as nove cenas. Neste formulário consta uma tabela, em que para cada cena numerada são dadas as opções de frequência: nunca, raramente, às vezes, frequente e muito frequente. Logo após cada rápida dramatização (em média de 2 a 3 minutos), o público foi instruído a responder marcando com um " $x$ " com que frequência se dá a situação recém-representada. $\mathrm{O}$ formulário também pede que a pessoa autodeclare seu gênero para que possibilitasse uma análise de reação quanto a este fator.

O mote das pequenas dramatizações durante o evento foi, essencialmente, desdobrar uma discussão sobre a temática de o assédio moral estar relacionado ao gênero feminino principalmente no ambiente profissional. Este tema é relevante não somente no âmbito acadêmico, mas também social, uma vez que o Brasil, segundo dados da OMS de 2013, reiterados no Mapa da Violência de $2015^{2}$, está classificado como o quinto país mais violento para mulheres no mundo. Ademais, o objetivo estendeu-se igualmente em levantar questões humanísticas acerca das relações interpessoais baseadas, em sua grande maioria, nos discursos hegemônicos advindos da sociedade estruturalmente patriarcal e heteronormativa. Através desta atividade esperase possibilitar ao(à) espectador(a), a partir do conceito do Teatro Didático ${ }^{3}$ [Brecht 1978], assimilar conteúdos de natureza da violência subjetiva, como o assédio moral, explicitado nas pequenas dramatizações.

Na próxima seção apresentamos os resultados gerados a partir das respostas fornecidas pelos(as) participantes do evento.

\section{Análise e Discussão dos resultados}

Os formulários foram respondidos por 32 pessoas: 6 do gênero masculino, 21 do gênero feminino e 5 optaram por não responder a essa informação. É interessante notar que a maioria do público do evento se autodeclarou do gênero feminino. $\mathrm{O}$ fato surpreende, pois, a instituição de ensino tem mais estudantes do gênero masculino matriculados ${ }^{4}$. No total foram representadas 9 cenas, porém, aqui discutimos alguns resultados que se destacam, principalmente quanto à reação discrepante entre o público declarado masculino e à do público declarado feminino.

\footnotetext{
${ }^{1} \mathrm{O}$ texto integral produzido para essa apresentação pode ser encontrado em: http://bit.ly/dim17cenas

${ }^{2}$ http://www.mapadaviolencia.org.br/pdf2015/MapaViolencia_2015_mulheres.pdf

3 Teatro Didático foi desenvolvido por Bertolt Brecht, na Alemanha, entre os anos de 1928 e 1932. As peças teatrais tinham teor político e social e o trabalho consistia em apresentá-las em fábricas e escolas sem preparação prévia dos atores

${ }^{4}$ Em 2017.1, por exemplo, em Sistemas de Informação: 298 homens e 55 mulheres matriculadas(os). Engenharia de Computação: 372 homens e 48 mulheres matriculadas(os). Conforme dados informados pelo coordenador do curso de Sistemas de Informação em 31/03/2017.
} 
Na Cena 1 um homem e uma mulher, de currículos igualmente importantes, são apresentados em uma reunião de trabalho. Entretanto, o currículo do homem é enfatizado e o da mulher é totalmente ignorado. Conforme mostra a Figura 1, a percepção de frequência desta situação pelo público autodeclarado masculino é, em sua maioria, retratada como se nunca ocorresse. Diferentemente do público autodeclarado feminino, em que a percepção é bem variada, porém apenas $14,3 \%$ acredita que nunca ocorre. Com esta discrepância podemos observar como é comum para as pessoas do gênero masculino não perceberem a ocorrência desse tipo de situação, retomando e reiterando conceitos do sociólogo francês Pierre Bourdieu (1989) sobre poder simbólico, um sistema cultural, histórico e linguístico que, a partir de diferentes linguagens, privilegia a figura masculina e o discurso patriarcal que domina as mais diversas esferas do social.

Cena 1: Feminino

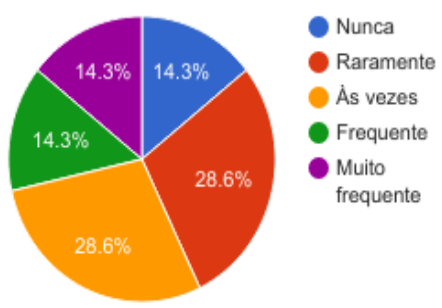

Cena 1: Masculino

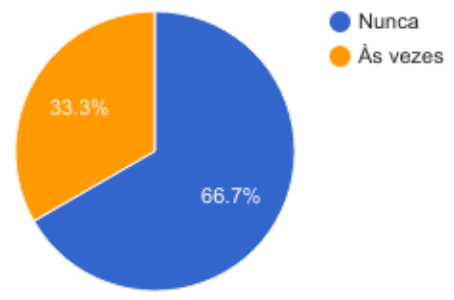

(a)

(b)

Figura 1: Reações do público feminino (a) e masculino (b) à Cena 1.

A Cena 2 relata uma avaliação docente pelo discente onde o uso de maquiagem e as roupas utilizadas pela professora se tornam alvo de crítica, enquanto que a avaliação deveria ter o foco na prática docente da professora e não na sua aparência. Esta expectativa retrata a valorização excessiva da profissional mulher de acordo com sua aparência e não conforme o seu currículo, como relatado na Cena 1. A Figura 2 mostra novamente a discrepância de percepção por parte do público masculino tendo declarado, em sua maioria, como se nunca ocorresse, e mesmo quando sinalizam que ocorre, ainda é de forma rara.

Cena 2: Feminino

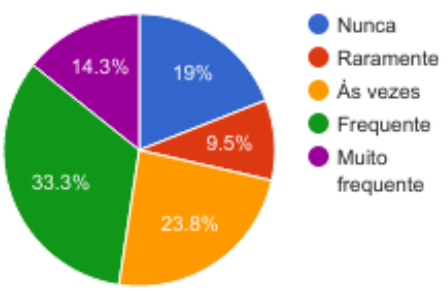

(a)

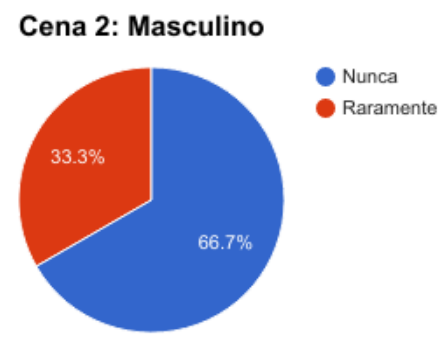

(b)

Figura 2: Reações do público feminino (a) e masculino (b) à Cena 2. 
A Cena 4 trata do preconceito em casa com relação ao interesse de mulheres por áreas culturalmente consideradas masculinas. Essa é uma questão relevante, principalmente no contexto do projeto Emíli@s pois, para atrair meninas para a área de Computação, também é importante perceber os fatores que limitam este interesse. A percepção do público feminino foi, em sua maioria muito frequente, enquanto que para o público masculino ficou dividido em raramente e frequente.

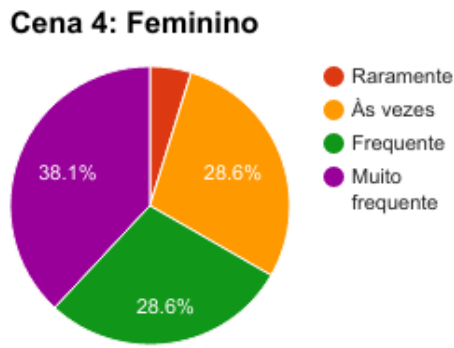

(a)

\section{Figura 3: Reações do público feminino (a) e masculino (b) à Cena 4.}

Com exceção da Cena 6, para todas as demais cenas o público autodeclarado do gênero masculino não assinalou a opção muito frequentemente. Entretanto, vale ressaltar que para a Cena 6 apenas 1 pessoa (de 6) do gênero masculino marcou esta alternativa, enquanto 13 (de 21) do gênero feminino marcaram esta opção.

Nos casos dramatizados, o papel da mulher como sendo subordinada à figura masculina e não assumindo papeis de destaque e liderança no que tange à área profissional é naturalizado, configurando, portanto, ao comparar as respostas do gênero feminino e masculino, uma reiteração de estereótipo do gênero feminino na visão do masculino.

\section{Considerações finais}

Esta primeira experiência já revela que a percepção das situações de preconceito de gênero é muito distinta para o público feminino e o público masculino. $\mathrm{O}$ fato de $\mathrm{o}$ evento ter maior participação do público feminino, embora tenha sido realizado em uma instituição cuja maioria do corpo discente é do gênero masculino, já indica que um evento que tem referência às mulheres não atrai o público masculino.

As reações do público masculino nos mostra que as ações de conscientização com relação a preconceito devem buscar mais a sensibilização do público masculino e externalizando como essas situações podem ser tratadas. Além disto, iniciativas como essa, de representar as cenas de preconceito por meio de Teatro Didático, podem ser uma forma lúdica de aproximação da realidade ao público alvo.

\section{Referências}

BOURDIEU, P. (1989) O poder simbólico. Rio de Janeiro: Bertrand Brasil S.A, 1989.

BRECHT, B. (1978) Estudos sobre teatro. Trad. F. P. Brandão. Rio de Janeiro: Nova Fronteira, 1978.

NUNES, M.A.S.N., LOUZADA, C., SALGUEIRO, E., ANDRADE, B., LIMA, P.S., MONTEIRO, R. (2016) Mapeamento de iniciativas brasileiras que fomentam a entrada de mulheres na computação. In.: Anais do XXXVI Congresso da Sociedade 
Brasileira de Computação. X WIT - Women in Information Technology. pp. 2697 2701.

NUNES, M.A.S.N., LOUZADA, C., SALGUEIRO, E., ANDRADE, B., LIMA, P.S., MONTEIRO, R. (2016) Mapeamento de iniciativas estrangeiras que fomentam a entrada de mulheres na computação. In.: Anais do XXXVI Congresso da Sociedade Brasileira de Computação. X WIT - Women in Information Technology. pp. 2692 2696. 